\title{
¿AUTONOMÍA DE LA VOLUNTAD EN EL DERECHO DE LAS FAMILIAS? OPINIONES SOCIO-JURÍDICAS SOBRE FILIACIÓN DE USUARIOS DE TÉCNICAS DE REPRODUCCIÓN HUMANA ASISTIDA CON DONACIÓN DE GAMETOS Y/O GESTACIÓN POR SUSTITUCIÓN*
}

\author{
AUTONOMY OF WILL IN THE RIGHT OF FAMILIES? SOCIO-LEGAL \\ OPINIONS ON THE FILIATION OF USERS OF ASSISTED HUMAN \\ REPRODUCTION TECHNIQUES WITH DONATION OF GAMETOS AND/OR \\ GESTATIONAL SURROGACY
}

\author{
Cecilia StraW ${ }^{* *}$
}

\begin{abstract}
Resumen: El objetivo del artículo es describir y analizar cómo se puso de manifiesto la autonomía de la voluntad en usuarios de las técnicas de reproducción humana asistida que recurrieron a la donación de gametos -óvulos y/o espermatozoides-o a la gestación por sustitución para conformar familias nucleares así como monoparentales, homoparentales o comaternales en la Argentina. Los usuarios resaltaron la importancia de las cuestiones vinculadas a la filiación haciendo referencia al contexto individual, sociocultural y legal en el cual tomaron las decisiones reproductivas.
\end{abstract}

Palabras clave: autonomía de la voluntad; filiación, técnicas de reproducción humana asistida, modelos de familias.

Abstract: The objective of the article is to describe and analyse how the autonomy of the will was manifested in users of assisted human reproduction techniques where the donation of gametes -ovules and / or spermatozoids- or gestational surrogacy were used to form nuclear families as well as single-parent, homo-parental or co-maternal families in Argentina. The users highlighted the importance of issues related to filiation by referring to the individual, sociocultural and legal context in which reproductive decisions were made.

Keywords: autonomy of the will, filiation, assisted human reproduction techniques, models of families.

* $\quad$ http://doi.org/10.15366/rjuam2018.38.009

Fecha de recepción: 28 de octubre de 2018.

Fecha de aceptación: 19 de diciembre de 2018.

** Doctora en Ciencias Sociales por la Universidad de Buenos Aires (Buenos Aires, Argentina). Profesora de la Carrera de Ciencia Política y de la Carrera de Ciencias de la Comunicación en la Facultad de Ciencias Sociales de la UBA. Investigadora Externa en el Área Salud, Economía y Sociedad del Centro de Estudios de Estado y Sociedad (CEDES). Correo electrónico: cecilia.straw@gmail.com. El presente artículo refleja los contenidos de la ponencia impartida en el Congreso Internacional «Desafíos actuales de la autonomía de la voluntad en las relaciones familiares y sus límites». Universidad Adolfo Ibáñez (Chile). Santiago de Chile 25 al 27 de septiembre 2018. 
SUMARIO: I. INTRODUCCIÓN; II. EL CONTEXTO NORMATIVO EN LAARGENTINA; III. LAAUTONOMÍA DE LA VOLUNTAD EN USUARIOS DE TRHA: LAS DECISIONES EN SUS PROPIAS PALABRAS; 1 . Los procesos de toma de decisiones reproductivas; A. Los modelos de familia monoparental, homoparental o comaternal; B. Las particulares y preferencias por la GS; 2. La filiación bio-genética y la filiación con donación de gametos: ¿Es un hijo propio? ¿Me reconocerá como madre? ¿Me querrá igualmente?; 3 . La figura de donante y de la gestante y sus interpretaciones en relación con la filiación; A. Las particularidades del donante conocido o intrafamiliar; 4. Las particularidades de la GS: la importancia de la regulación legal del tratamiento y de la filiación; IV. CONCLUSIONES; V. BIBLIOGRAFÍA.

\section{INTRODUCCIÓN}

Este artículo se titula ¿autonomía de la voluntad en el derecho de las familias? porque el objetivo es describir y analizar cómo se puso de manifiesto la autonomía de la voluntad en usuarios de las técnicas de reproducción humana asistida (TRHA) que recurrieron a la donación de gametos -óvulos y/o espermatozoides- y/o a la gestación por sustitución (GS) para conformar diferentes modelos de familias con hijos en la Argentina.

Desde la perspectiva antropológica -luego de la crítica de Schneider ${ }^{1}$ al carácter etnocéntrico del concepto de parentesco, redefiniendo su pertinencia analítica a las sociedades occidentales donde se distingue entre sus componentes biológicos y sociales-, en los años noventa se desarrolló una corriente que focalizó sus estudios en la complejidad que adquiere la definición de los vínculos de parentesco en contextos tecnológicos. Esto se explica por el hecho de que el uso de las TRHA interfiere tanto en los aspectos biológicos como en los aspectos relacionales de la concepción dominante del parentesco euro-americana.

En el primer caso, las tecnologías reproductivas intervienen en los aspectos biogenéticos porque alteran la base de significación a partir de la cual se establecen los vínculos de parentesco. Esta intervención provoca consecuencias ${ }^{2,3}$ : por un lado, representa la fragmentación del proceso reproductivo único al desarticular en la práctica lo que los euro-americanos conciben como un nexo de eventos naturales -coito, concepción y nacimiento-. Por otro lado, significa la multiplicación del número de personas que pueden estar involucradas en el nacimiento de un ser humano. Y finalmente, dichas tecnologías introducen ambigüedad o incerteza en la definición de los lazos de parentesco biológicos, los que en ausencia de las TRHA eran considerados irrevocables.

SCHNEIDER, D., A Critique of the Study of Kinship, Ann Arbor (University of Michigan Press), 1984.

2 STRATHERN, M., Reproducing the future: Anthropology, kinship and the new reproductive technologies, New York (Routledge), 1992.

3 STRATHERN, M., «A Antropologia e o advento da Fertilização In Vitro no Reino Unido: uma história curta». Caderno Pagu, núm. 33, 2009, pp. 9-55. 
En el segundo caso, el uso de las TRHA afecta los aspectos relacionales del parentesco a partir de los cuales se construyen los vínculos sociales y se conforman, en paralelo, las identidades personales y familiares de las personas ${ }^{4,5}$. Aquí la existencia de semejanzas físicas entre padres e hijos juega un rol importante al evidenciar las verdades de la biología en el parentesco, y confirmar la relación de conyugalidad entre un hombre y una mujer. Precisamente a partir de las semejanzas físicas los padres sitúan a sus hijos/hijas en una red de lazos familiares donde se generan relaciones de identificación tanto individual como familiar, y no sólo por el hecho de compartir una herencia genética sino porque se desarrollan lazos de afecto entre los integrantes familiares ${ }^{3}$. En consecuencia de la confluencia de los aspectos bio-genéticos y relacionales del parentesco se deriva que «madre cierta es» dado que será madre la mujer que pare a un niño o una niña y se presumirá que es el padre el marido de la madre.

Esta descripción analítica sobre las consecuencias del uso de las tecnologías reproductivas permite introducir la profunda ruptura cultural que significa para la concepción dominante del parentesco recurrir a material genético de otras personas para realizar los tratamientos con donación de óvulos y/o espermatozoides, como a otra persona para realizar una GS. Las tecnologías reproductivas permiten tener un hijo o una hija con quien se comparta unilateralmente elementos bio-genéticos y compatibilizar semejanzas físicas a partir de la selección de rasgos similares en los donantes. También permiten tener un hijo o una hija con quien se comparta (o no) elementos genéticos y, a la vez, no se tenga vinculación biológica porque no se ha podido gestarlo/a ni parirlo/a. Un paso posterior al que nos referiremos en el siguiente apartado es el reconocimiento jurídico del vínculo paterno-filial y las responsabilidades parentales cuando son consecuencia del uso de las TRHA.

Desde la perspectiva jurídica, analizar la autonomía de la voluntad en el derecho de las familias en la Argentina nos obliga a hacer referencia al contenido del artículo 19 de la Constitución ${ }^{6}$ en lo relativo a la reserva de la intervención estatal, en las acciones privadas de las personas que no ofendan al orden, la moral pública, ni perjudiquen a un tercero por lo que quedan exentas de la autoridad de los magistrados. Y también al hecho que las personas no estarán obligadas a hacer lo que la ley no manda ni privadas de lo que ella no prohíbe. Este artículo es de crucial importancia dado que deja establecido el margen de libertad en el que los usuarios de TRHA podrán decidir para conformar los diferentes modelos de familias.

4 MARRE, D. y BESTARD, J., La adopción y el acogimiento. Presente y perspectivas, Barcelona (Universitat de Barcelona), 2004.

5 BESTARD, J., «Los hechos de la reproducción asistida: entre el esencialismo biológico y el constructivismo social». Revista de Antropología Social, Universidad Complutense de Madrid, núm. 18, 2009, pp. 83-95.

6 ARGENTINA. CONSTITUCIÓN NACIONAL. Artículo 19: Las acciones privadas de los hombres que de ningún modo ofendan al orden y a la moral pública, ni perjudiquen a un tercero, están sólo reservadas a Dios, y exentas de la autoridad de los magistrados. Ningún habitante de la Nación será obligado a hacer lo que no manda la ley, ni privado de lo que ella no prohíbe. Disponible en <http://servicios.infoleg.gob.ar/ infolegInternet/anexos/0-4999/804/norma.htm> [Consultado el 05/09/2018]. 
En particular, para el análisis de la autonomía de la voluntad en el derecho de las fami$\operatorname{lias}^{7}$ en las experiencias de los usuarios de TRHA tomaremos como referencia la definición enunciada por Nelly Minyersky:

«Cada individuo goza de su derecho a la autodeterminación en cada una de sus decisiones personales. La familia conforma una faceta más en la vida de las personas, y no queda exenta de esa autonomía de la voluntad. [...] Lo cierto es que los cambios sociales llevan siempre muchos años de gestación y desarrollo para imponerse sobre otros, y ellos llevan la impronta de la voluntad de cada uno de los individuos que han vivido en esas épocas. Las diferentes y múltiples formas familiares que existen en nuestra sociedad, si bien son el resultado de años de gestación, también son el resultado del reconocimiento de la autonomía de la voluntad de los individuos, no sólo sobre su propia vida, sino sobre su vida familiar. Cada individuo, más allá del derecho positivo del lugar en el que vive, decide formar su familia del modo en que lo considere apropiado. Este modelo nuevo de familia nace en un modelo democrático, en tanto los individuos además de respetar su libre determinación, o su autonomía personal, respetan la del resto de los integrantes de la familia, y basados en principio de tolerancia y solidaridad crean su propio modelo de familia».

\section{EL CONTEXTO NORMATIVO EN LA ARGENTINA}

Las aplicaciones de las tecnologías reproductivas para conformar diferentes modelos de familias derivan en transformaciones en el campo jurídico al tener que determinar los vínculos filiales y las responsabilidades parentales. En relación con ello, la reforma del Código Civil y Comercial de la Argentina (CCyC) ${ }^{9}$, vigente desde el 1 de agosto de 2015, constituye una respuesta a algunas de las cuestiones vinculadas a la conformación de familias en contextos tecnológicos ${ }^{10}$. Sin embargo, antes de describir los respectivos contenidos

7 Para profundizar sobre la autonomía de la voluntad en el derecho de familia argentino, vid. KEMELMAJER DE CARLUCCI, A., «La autonomía de la voluntad en el derecho de familia argentino», en GRAHAM, M. y HERRERA, M. (dirs.), Derecho de las Familias, Infancia y Adolescencia. Una mirada crítica y contemporánea, 1. ${ }^{\mathrm{a}}$ ed., Ciudad Autónoma de Buenos Aires (Infojus), 2014, pp. 3-43. Disponible en $<$ http://www.saij.gob.ar/ aida-kemelmajer-carlucci-autonomia-voluntad-derecho-familia-argentino-dacf140453-2014-07/1234567890abc-defg3540-41 fcanirtcod> [Consultado el 05/09/2018].

8 MINYERSKY, N., «El impacto del proyecto del Código Civil y Comercial de la Nación en instituciones del derecho de familia», Revista Pensar en Derecho, vol. 1, núm. 0, 2012, pp.69-115. Disponible en <http:// www.derecho.uba.ar/publicaciones/pensar-en-derecho/revistas/0/el-impacto-del-proyecto-del-codigo-civil-ycomercial-de-la-nacion-en-instituciones-del-derecho-de-familia.pdf $>$ [Consultado el 05/09/2018].

9 ARGENTINA. CÓDIGO Civil y Comercial de la Nación. 1 $1^{\mathrm{a}}$ ed. Buenos Aires: Infojus, 2014.

10 Como sostuvieron integrantes del equipo redactor del anteproyecto de reforma del Código Civil y Comercial argentino, «el anteproyecto no pretende crear algo absolutamente original; por el contrario, nos hemos nutrido de los avances operados en otros países que vienen ocupándose del tema desde hace varios años». Y las referencias a los antecedentes en el derecho comparado considerados se encuentran publicadas 
resulta necesario detenernos en dos antecedentes legales vinculados al derecho a formar una familia con independencia de la orientación sexual de las personas ${ }^{11}$ que muestran las particularidades del contexto de cambios socio-culturales y normativos con el cual la reforma del Código tenía que entrar en consonancia.

El primer antecedente es la ley $26618 / 2010^{12}$ conocida coloquialmente como la ley de matrimonio igualitario que extiende la institución del matrimonio civil a las parejas del mismo sexo, legalizando de esta forma la conformación de familias diferentes al predominante modelo hetero-normativo. Otro punto trascendental de esta ley es que prevé la paternidad y maternidad compartida en dichas parejas, quienes indefectiblemente deben recurrir a las tecnologías reproductivas para convertirse en madres o padres ${ }^{13}$.

El segundo antecedente que favorece la efectividad del derecho a formar una familia con independencia de la orientación sexual de sus integrantes es la ley 26862/2013 ${ }^{14} \mathrm{de}$ acceso integral a los tratamientos de reproducción humana médicamente asistida. En ella se reconoce el acceso a los tratamientos de baja y alta complejidad, con la donación de gametos y/o embriones, y se lo incorpora a la cobertura del Plan Médico Obligatorio ${ }^{15} \mathrm{a}$ cargo del sistema público de salud, las obras sociales y las entidades de medicina prepaga. Los destinatarios de estos servicios de salud son todas las personas mayores de 18 años sin exclusiones por orientación sexual o estado civil, y los menores de edad con enfermedades que afecten la capacidad futura de procrear $^{16}$.

en KEMELMAJER DE CARLUCCI, A., HERRERA, M., y LAMM, E., «Ampliando el campo del derecho filial en el derecho argentino. Texto y contexto de las técnicas de reproducción humana asistida», Revista de Derecho Privado, vol. 1, núm. 1, 2012, pp. 3-45. Disponible en $<$ http://www.uba.ar/archivos_ddhh/image/2012RevistaInfojusFinal.pdf $>$ [Consultado el 20/01/2019].

11 Para profundizar sobre el derecho a formar una familia en el contexto normativo argentino, vid. HERRERA, M., «¿Existe un derecho al hijo? El lugar y los límites de las técnicas de reproducción humana asistida», RJUAM, núm. 35, 2017, pp. 73-113.

12 ARGENTINA. Ley n. $^{\circ} 26618,15$ de julio 2010. Ley de matrimonio entre personas del mismo sexo (matrimonio igualitario). Boletín Oficial, 22 y 23 de Julio de 2010. Disponible en $<$ http://www.saij.gob. ar/26618-nacional-matrimonio-entre-personas-mismo-sexo-modificacion-al-codigo-civil-lns0005610-201007-15/123456789-0abc-defg-g01-65000scanyel?> [Consultado el 5/9/18].

13 Para profundizar sobre los aspectos particulares que adquiere la filiación en parejas homoparentales, vid. KEMELMAJER DE CARLUCCI, A., HERRERA, M., y LAMM, E., «Filiación y homoparentalidad. Luces y sombras de un debate incómodo y actual». Revista La Ley, núm. 1, 2010, pp. 1 y ss.

14 ARGENTINA. Ley n. ${ }^{\circ} 26862,5$ de Junio de 2013. Ley de reproducción médicamente asistida. Boletín Oficial, 26 de junio de 2013. Disponible en $<$ http://www.saij.gob.ar/26862-nacional-ley-reproduccionmedicamente-asistida-lns0005848-2013-06-05/123456789-0abc-defg-g84-85000scanyel> [Consultado el 5/9/18].

15 El Programa Médico Obligatorio es el conjunto de prestaciones básicas garantizadas por los agentes del seguro de salud. Resolución del Ministerio de Salud de la Nación N. ${ }^{\circ}$ 201/2002. Disponible en <http:// servicios.infoleg.gob.ar/infolegInternet/verNorma.do?id=73649> [Consultado el 5/9/18].

16 Para profundizar sobre los contenidos y comentarios de la ley 26862, vid. HERRERA, M., LAMM, E., «Cobertura médica de las técnicas de reproducción asistida. Reglamentación que amplía el derecho humano a formar una familia», Revista La Ley, núm. 140, 2013, pp. 1-6. 
Con estos antecedentes, el CCyC introdujo en su articulado el reconocimiento como tercer tipo filial autónomo el derivado de las TRHA equiparando este tipo de acceso a la filiación con la filiación por naturaleza y la filiación por adopción (artículo 558). Asimismo incorporó la figura de voluntad procreacional para asignar los derechos y las obligaciones derivados de la filiación recurriendo a las tecnologías reproductivas (artículo 562) ${ }^{17}$. La voluntad procreacional se reconoce a quien la haya manifestado con la firma de un consentimiento -cuyos rasgos deben ser libre, previo e informado- para convertirse en madre o padre sin importar si aportó o no los gametos (artículos 560 y 561) $)^{18}$.

En particular respecto de los artículos del CCyC mencionados resulta importante diferenciar el fundamento a partir del cual se atribuye la filiación de acuerdo al tipo filial por naturaleza o el derivado de las técnicas reproductivas. La filiación por naturaleza se funda en el derecho biológico, por el contrario, la filiación derivada de las tecnologías reproductivas se funda en el elemento volitivo. Así se desplaza la importancia de la existencia del vínculo genético y se otorga relevancia a la existencia del consentimiento o voluntad procreacional ${ }^{19}$. Esta distinción quedó expresamente plasmada en el artículo 575 que establece que la determinación de la filiación en los supuestos de TRHA se deriva del consentimiento previo, informado y libre, prestado de conformidad con lo dispuesto en el CCyC y la ley especial -la cual en estos tres años de vigencia del CCyC no ha sido sancionada-.

Otros dos aspectos respecto de la importancia del consentimiento informado y la voluntad procreacional vinculados al ejercicio de la autonomía de la voluntad y la filiación merecen resaltarse. Por un lado, la necesidad de renovación del consentimiento informado cada vez que se procede a la utilización de gametos o embriones (artículo 560). Por otro lado, la imposibilidad de impugnación de la filiación una vez suscripto el consentimiento libre, previo e informado con independencia de quién haya aportado los gametos (artículo 577). Tal es la importancia atribuida al consentimiento informado que Marisa Herrera lo

17 El texto del artículo 562 describe a la voluntad procreacional y al procedimiento administrativo a seguir respecto del consentimiento informado en los siguientes términos: «ARTICULO 562.-Voluntad procreacional. Los nacidos por las técnicas de reproducción humana asistida son hijos de quien dio a luz y del hombre o de la mujer que también ha prestado su consentimiento previo, informado y libre en los términos de los artículos 560 y 561, debidamente inscripto en el Registro del Estado Civil y Capacidad de las Personas, con independencia de quién haya aportado los gametos». Como analizaremos posteriormente la expresión «quien dio a luz» tendrá implicancias jurídicas en quienes tengan un/a hijo/a por GS en la Argentina.

18 Para profundizar sobre la regulación de las TRHA en otros países y el recurso a la figura de voluntad procreacional, vid. HERRERA, M. y LAMM, E., «Una trilogía sobre las bases constitucionales del derecho filial en el Anteproyecto de reforma del Código Civil: Técnicas de reproducción humana asistida (Bleu)», Diario Microjuris, (MJAR), Buenos Aires, 2012, pp. 1-29; y LAMM, E., «La importancia de la voluntad procreacional en la nueva categoría de filiación derivada de las técnicas de reproducción asistida», Revista de Bioética y Derecho, núm. 24, 2012, pp. 76-91.

19 Para profundizar sobre los aspectos particulares que adquiere la filiación en contextos tecnológicos, vid. HERRERA, M., DE LA TORRE, N., SALITURI AMEZCUA, M., RODRÍGUEZ ITURBURU, M., y VITTOLA, L., «Capítulo V: Filiación derivada de técnicas de reproducción humana asistida: voluntad procreacional y consentimiento informado» en HERRERA, M. (dir.), Técnicas de Reproducción Humana Asistida, Buenos Aires (Rubinzal - Culzoni Editores), 2018, p. 585. 
denomina como un tema neurálgico porque «la falta de consentimiento o su revocación antes de la concepción o implantación no permite que la práctica médica se lleve a cabo. Y en el supuesto excepcional en que se proceda a la implantación a pesar de la negativa o sin renovar el consentimiento de uno de los integrantes de la pareja, éste estaría facultado a impugnar el vínculo filial»» ${ }^{20}$.

El reconocimiento de solo dos vínculos filiales es otro aspecto importante en los casos en que se utilizan las TRHA con la donación de gametos. El CCyC en las disposiciones generales establece que ninguna persona puede tener más de dos vínculos filiales, cualquiera sea la naturaleza de la filiación (artículo 558). Este artículo es trascendente porque refuerza la lógica regulatoria del Código en la cual los donantes de ninguna manera pueden ser considerados progenitores -forma genérica para referirse a la filiación en parejas de igual o de diverso sexo- sino que son terceros ajenos al vínculo filial que se genera ${ }^{21}$.

Finalmente el CCyC (artículo 2634) aborda los casos en que el nacimiento utilizando TRHA haya ocurrido de acuerdo al derecho extranjero, y establece que el emplazamiento filial debe ser reconocido en el país conforme a nuestros principios de orden público y especialmente aquellos que imponen considerar prioritariamente el interés superior del niño. Este artículo marcará la diferencia y las vicisitudes que pueden tener que afrontar en los trámites de filiación las personas o parejas que recurren a la GS en la Argentina o en el extranjero.

Por último, la regulación de la GS estaba prevista en el anteproyecto de reforma del CCyC redactado por la Comisión Elaboradora ${ }^{22}$ pero en el dictamen la Comisión Bicameral integrada por diputados y senadores nacionales suprime el articulado con los siguientes argumentos:

«[La GS] es la figura jurídica que más voces encontradas ha generado. [...] La especialidad y mayor complejidad de esta técnica de reproducción humana es la única que involucraba un proceso judicial previo. [Además la Comisión considera que] la GS encierra dilemas éticos y jurídicos de gran envergadura que ameritaría un debate más profundo de carácter interdisciplinario. En este contexto de incertidumbre y cuasi silencio legal en el derecho comparado, se propone de manera precautoria, eliminar la GS del proyecto de reforma $)^{23}$.

20 HERRERA, M., DE LA TORRE, N., SALITURI AMEZCUA, M., RODRÍGUEZ ITURBURU, M., y VITTOLA, L., «Capítulo V: Filiación derivada de técnicas de reproducción humana asistida: voluntad procreacional y consentimiento informado», ob. cit. p. 551.

${ }^{21}$ HERRERA, M., DE LA TORRE, N., SALITURI AMEZCUA, M., RODRÍGUEZ ITURBURU, M., y VITTOLA, L., «Capítulo V: Filiación derivada de técnicas de reproducción humana asistida: voluntad procreacional y consentimiento informado», ob. cit. p. 456.

22 La Comisión para la Elaboración del Proyecto de Ley de Reforma, Actualización y Unificación de los Códigos Civil y Comercial de la Nación estuvo integrada por dos Jueces de la Corte Suprema de Justicia de la Nación y una ex Jueza de la Corte Suprema de Justicia de la Provincia de Mendoza.

23 CÁMARA DE DIPUTADOS DE LA NACIÓN. SESIONES ORDINARIAS 2014. Anexo al ORDEN DEL DÍA No 829. Disponible en <https:/www4.hcdn.gob.ar/dependencias/dcomisiones/periodo-132/132829Anexo.pdf> [Consultado el 05/09/2018]. 
Por el contrario, la Comisión Elaboradora fundamentaba la regulación de la GS en el principio de realidad ya que desde 2010 se había comenzado a tramitar un caso en la justicia ordinaria $^{24}$, y en la aplicación de los principios de libertad, igualdad y no discriminación entre matrimonios heterosexuales y homosexuales en consonancia con la ley de matrimonio igualitario vigente desde 2010. También la regulación de la GS se fundaba en el principio de no discriminación entre personas lesbiana y gays y el consiguiente derecho a formar una familia con independencia de la orientación sexual de las personas ${ }^{25}$. Su propuesta consistía en que:

«El consentimiento informado y libre de todas las partes intervinientes en el proceso de gestación por sustitución debe ajustarse a lo previsto por este Código y la ley especial. La filiación queda establecida entre el niño nacido y el o los comitentes mediante la prueba del nacimiento, la identidad del o los comitentes y el consentimiento debidamente homologado por autoridad judicial. El juez debe homologar sólo si, además de los requisitos que prevea la ley especial, se acredita que: (a) se ha tenido en miras el interés superior del niño que pueda nacer; (b) la gestante tiene plena capacidad, buena salud física y psíquica; (c) al menos uno de los comitentes ha aportado su material genético; (d) el o los comitentes poseen imposibilidad de concebir o de llevar un embarazo a término; (e) la gestante no ha aportado material genético propio; (f) la gestante no ha recibido retribución; (g) la gestante no se ha sometido a un proceso de gestación por sustitución más de dos (2) veces; (h) la gestante ha parido, al menos, un hijo propio. Los médicos no pueden proceder a la implantación de la gestante sin la autorización judicial. Si se carece de autorización judicial previa, la filiación se determina por las reglas de la filiación por naturaleza» ${ }^{26}$.

En la opinión de Notrica y Curti, frente a la inexistencia de una norma jurídica que regule la GS en la Argentina, la jurisprudencia anterior y posterior a la reforma del CCyC «hasta ahora de manera unánime, ha consolidado la aceptación de la GS por cuanto todas sus decisiones fueron favorables; razón por la cual revaloriza o reafirma la importancia que el Congreso de la Nación sancione una ley especial $»^{27}$.

24 NOTRICA, F. y CURTI, P. «Capítulo VI: Gestación por sustitución» en Técnicas de Reproducción Humana Asistida, Buenos Aires (Rubinzal - Culzoni Editores), 2018, p.37.

25 MORENO, G. «Legislar sobre la vida. Los saberes autorizados y la regulación sobre la gestación por sustitución en la Argentina» en STRAW, C., VARGAS, E., VIERA CHERRO, M., TAMANINI, M. (coords.), Reprodução assistida e relações de gênero na América Latina, Editora CRV, Curitiba, 2016.

26 KEMELMAJER DE CARLUCCI, A., HERRERA, M., y LAMM, E., «Ampliando el campo del derecho filial en el derecho argentino. Texto y contexto de las técnicas de reproducción humana asistida», ob. cit. p. 40.

27 Para profundizar en el análisis pormenorizado y actualizado de la jurisprudencia de los casos de gestación por sustitución en la Argentina, vid. NOTRICA, F. y CURTI, P. «Capítulo VI: Gestación por sustitución» en en HERRERA, M. (dir.), Técnicas de Reproducción Humana Asistida», Buenos Aires (Rubinzal - Culzoni Editores), 2018, pp. 9-142. 


\section{LA AUTONOMÍA DE LA VOLUNTAD EN USUARIOS DE TRHA: LAS DECISIONES EN SUS PROPIAS PALABRAS ${ }^{28}$}

Seleccionamos cuatro temas donde se pone de manifiesto la autonomía de la voluntad de los usuarios de TRHA. En ellos se le asigna importancia a las cuestiones entorno de la filiación y se hace referencia al contexto individual, cultural y legal en el cual se tomaron las decisiones y se realizaron los tratamientos con donantes y/o gestantes.

\section{Los procesos de toma de decisiones reproductivas}

El análisis de las opiniones de los usuarios de tratamientos reproductivos con donantes y/o gestante muestra que las decisiones que toman para conformar sus familias con hijos delinean un proceso signado, en las experiencias de parejas heterosexuales, por las trayectorias de atención médica donde los resultados negativos e inesperados (esterilidad, infecundidad, tratamientos reproductivos fallidos) son los que establecen las opciones sobre las cuales pueden decidir los pasos a seguir. Así los usuarios evalúan las diferentes alternativas que brindan los tratamientos con ovo y/o espermadonación los que inicialmente no siempre habían sido considerados como las vías para tener un/a hijo/a. Por el contrario, los entrevistados que la infertilidad es de tipo estructural por ser mujeres sin pareja y parejas conformadas por gays o lesbianas, estos tratamientos así como la gestación por sustitución también son evaluados a lo largo de un proceso que se caracteriza por poner el foco en la resolución de los aspectos necesarios para su implementación.

La adopción como vía para tener hijos fue analizada por casi todos los entrevistados -y algunos de ellos habían realizado los trámites formales- pero finalmente resulta descartada por considerarla un proceso prolongado en el tiempo, sin la certeza respecto de la efectividad de llegar a adoptar un/a niño/a, o sentirse algunos de los entrevistados sujetos discriminados por su orientación sexual homosexual. Estas opiniones respecto de la descripción de la adopción de niños en la Argentina coincide con la de especialistas en temas de familia quienes sostuvieron que existen «innumerables complicaciones fácticas que padecen para adoptar incluso los que cumplen con las expectativas sociales (estar casados o en pareja estable, ser heterosexuales, encontrarse en condiciones económicas, sociales y ambientales buenas); en los casos que estos requisitos no se cumplen, no siempre explici-

28 Las opiniones de los usuarios que se presentan en este apartado fueron recogidas en el marco del Proyecto UBACyT «Hacia una ley especial sobre técnicas de reproducción humana asistida. Bioética, derechos humanos y familias». PROGRAMACIÓN CIENTÍFICA 2013-2016. Universidad de Buenos Aires. Facultad de Derecho (Buenos Aires, Argentina), Directora: Marisa Herrera. Se realizaron entrevistas en profundidad a 40 personas (32 mujeres y 8 varones). La descripción completa de las características y metodología utilizada en la investigación se encuentra en STRAW, C., DE LA TORRE, N., BLADILO, A., y SALITURI AMEZCUA, M., «Anexo II. Resultados de la investigación. Trayectorias sociojurídicas de la reproducción asistida cuando involucra a un tercero (donante o gestante). De identidades y filiaciones en plural» en HERRERA, M. (dir.), Técnicas de Reproducción Humana Asistida, Buenos Aires (Rubinzal - Culzoni Editores), 2018, pp. 588- 593. 
tados por la justicia, los inconvenientes para adoptar se multiplican y suelen convertirse en impedimentos infranqueables $\gg{ }^{29}$. Respecto de actitud frente a la adopción no emergieron diferentes opiniones de acuerdo al modelo de familia a conformar por los entrevistados.

En otras experiencias, la adopción se posiciona como una segunda opción a explorar en caso que los tratamientos reproductivos con donantes de gametos y/o gestantes fallen. Estas mismas opiniones se encontraron en otras investigaciones realizadas en la Argentina ${ }^{30}$ con usuarias de TRHA, heterosexuales, que se encontraban realizando tratamientos y todavía no habían tenido un/a hijo/a, y en el Reino Unido con parejas heterosexuales ${ }^{31}$.

Un aspecto preciso en donde se puso de manifiesto el ejercicio de la autonomía de la voluntad -en este caso sobre las decisiones reproductivas- fue que a lo largo del proceso de búsqueda del hijo/a se producen cambios de opinión frente a las opciones de los tratamientos disponibles. En algunas experiencias se menciona la realización de una terapia psicológica para favorecer la aceptación y la decisión de realizar alguno de ellos.

«Fue más doloroso todo el proceso de la búsqueda que aceptar que no funcionaba [algo en el sistema reproductivo]. Para mí fue como contundente y claro, es decir está bien, ya entendí, esto no funciona, y ahí a pensar opciones. Empezamos a pensar el tema de la adopción, y bueno surgió la posibilidad de la donación de óvulos» [E 3, pareja heterosexual, ovodonación].

«La verdad es que no tuve una aceptación inmediata [de la ovodonación]. Sinceramente necesitaba estar convencida de qué iba a ser, y si eso dentro de mi corazón era el camino a seguir. Un camino que no me cerraba era la adopción. [...] Y lo cierto es que fue un proceso. Quizás la única diferencia que en este proceso no estuvo - de información y de aceptación- es el dolor. Porque los otros procesos [realizar tratamientos reproductivos que fallaron] eran de "entusiasmo y de pérdida" y había que reponerse. Este quizás era más bien de "análisis y aceptación"; [...] y optamos por aceptar la donación de óvulos» [E 13, pareja heterosexual, ovodonación].

«En ese momento no se nos ocurría pensar en recibir una donación de esperma. Era poco probable. Pero el día que operan a mi marido y me extraen a mí [los óvulos] nos dicen: "no pudimos extraerle nada, así que tus óvulos los voy a congelar hasta que Uds. decidan qué quieren hacer". Ahí tardamos cuatro meses en definir qué íbamos a hacer porque no lo esperábamos. Y así empiezan todas las charlas de si

29 KEMELMAJER DE CARLUCCI, A., HERRERA, M., y LAMM, E., «Ampliando el campo del derecho filial en el derecho argentino. Texto y contexto de las técnicas de reproducción humana asistida», ob. cit. p. 17.

30 STRAW, C., Público y privado en la reproducción asistida: oposición permanente. Estudio cualitativo en mujeres de sectores populares y medios residentes en el Área Metropolitana de Buenos Aires. Berlín, (Editorial Publicia), 2014, pp. 93-151.

31 JENNINGS, S., MELLISH, L., TASKER, F., LAMB, M., GOLOMBOK, S., «Why adoption? Gay, lesbian, and heterosexual adoptive parents'reproductive experiences and reasons for adoption». Adopt Q, vol. 17, 2014, pp.205-226. 
deberíamos adoptar, qué es lo que puedo, qué es lo que quiero, y decidimos ir por la donación de esperma» [E1, pareja heterosexual, espermadonación].

Por último, los/as usuarios/as homosexuales y lesbianas entrevistados destacaron que la sanción de las leyes de matrimonio igualitario e identidad de género favorecieron la toma de decisiones reproductivas porque no solo otorgaron un reconocimiento legal al tipo de familias diversas que ellos querían conformar, sino porque esas leyes eran la muestra de un cambio cultural de apertura hacia la diversidad sexual y de tratamiento igualitario con las personas heterosexuales.

«Me parece que el marco normativo del matrimonio igualitario, ley identidad de género es un mensaje simbólico y cultural muy fuerte. Y en nuestro caso al ser una pareja de mujeres requiere mucha más planificación...Al menos sabíamos que por accidente no iba a ser. [...] Y lo que pensamos fue en buscar un donante en un banco que sea anónimo, y que la maternidad recaiga sobre nosotras dos. Ese es nuestro esquema" [las dos ser reconocidas legalmente como madres]» [E2, pareja de mujeres, espermadonación].

\section{A. Los modelos de familia monoparental, homoparental o comaternal}

La decisión de tener un/a hijo/a y conformar una familia monoparental, homoparental o comaternal -además de presentarse como un proceso en el que los usuarios de las TRHA toman las decisiones reproductivas- emergió con un rasgo distintivo cuando se evalúan circunstancias socio-culturales e individuales. En particular, los usuarios tienen miedos o dudas que giran en torno de la conformación de modelos familiares sin padre o madre o con dos padres o dos madres, y el grado de aceptación o de rechazo social de estos modelos familiares. Además cuando las mujeres sin parejas evalúan la alternativa para conformar una familia monoparental la edad y la fecundidad de la futura madre -la referencia al denominado reloj biológico de las mujeres- emergen como aspectos relevantes para no postergar la decisión de tener un hijo. Iguales resultados se registraron en una investigación realizada en los Estados Unidos en los años noventa ${ }^{32}$.

«Al principio yo pensé mucho el tema de que no tuviera papá. Eso sí lo pensé mucho y cómo sería nacer sin papá y cómo se sentiría al respecto. No es que fue liviano para mí. Y el tema del donante me sonaba que era lo más limpio, nadie y ningún ocultamiento» [E3, mujer sin pareja, espermadonación].

32 HERTZ, R., RIVAS, A.M., RUBIO JOCILES, M.I., «Single Mothers by Choice in Spain and the United States», en CONSTANCE, L. SHENAN (ed.), The Wiley Blackwell Encyclopedia of Family Studies, $1^{\text {a }}$ ed., New York (John Wiley \& Sons, Inc.), 2016, pp.1-5. Disponible en $<$ https://doi.org/10.1002/9781119085621. wbefs005> [Consultado el 20/01/2019]. 
«A mí me parece que si puede llegar a haber algún temor es justamente del contexto, fuera de nosotros, que le insista mucho [al niño/a] y la mamá, y la mamá, y la mamá. Siempre hay una edad en que los chicos no les creen tanto a los padres y les dan más bola al contexto» [E2, varón, pareja homosexual, GS extranjero]. «Una de las cosas que sale en la socialización es que no hay padre porque en nuestra familia no hay padre. Nuestra familia somos dos madres pero todas las familias son diferentes...Tenés familias como la de Francisco que vive con el abuelo...y la familia de Francisco es el abuelo» [E2, pareja de mujeres, espermadonación].

«Y dije si no pasa nada se me acaba el tiempo biológico... Entonces unas vacaciones dije: "actúo". Dejé de pensar, dejé de buscar, dejé de estar en el limbo. Cuando me preguntaron por qué no adoptó yo dije: "Yo quiero un embarazo". Y dado que por la genética no iba a ser mío por lo menos intentar un embarazo. Si no obviamente iba a adoptar. El tratamiento dependía todo de mí, una cuestión de plata» [E1, mujer sin pareja, ovo y espermadonación].

«Si yo el día de mañana llego a los 40 sin pareja, sin posibilidad de haber sido madre, de tener mi familia, proyecto de dos... ¡Y Yo hago lo mismo! Porque yo sé lo que es querer ser mamá. Ese fue el primer contacto con la realidad y dije: ¡Ya está; esta opción!» [E10, mujer sin pareja, espermadonación].

\section{B. Las particulares y preferencias por la GS}

Los usuarios que realizaron una GS para tener un/a niño/a también describieron un proceso de toma de decisiones reproductivas donde evalúan las alternativas y la viabilidad de las opciones para tener un hijo y formar una familia. Nuevamente la adopción fue considerada una opción remota, difícil de efectivizar por ser personas o parejas gays. Así la GS se impone como la única opción disponible y cuenta con el elemento positivo de permitir que el niño/a que nazca tenga un vínculo genético con el progenitor o alguno de ellos. Similares opiniones sobre el proceso de adopción aleatorio, donde incluso puede reclamarse al niño adoptado, así como permitir la vinculación genética entre padre e hijo/a fueron reportadas en un estudio realizado en los Estados Unidos sobre las motivaciones de parejas gays que recurren a la GS ${ }^{33}$. Entre las personas gays -al igual que en las mujeres heterosexuales sin pareja- la edad se menciona como un aspecto para no postergar la toma de decisiones pero con un argumento diferente: evitar tener hijos a edades avanzadas y sentirse más cercano a ser abuelos que padres.

El mismo recurso a la GS se les presenta a las parejas heterosexuales cuyas mujeres tenían problemas de salud que les imposibilitan gestar o llevar a término un embarazo.

33 BLAKE, L., CARONE, N., RAFFANELLO, E., SLUTSKY, J., EHRHARDT, A.A., and GOLOMBOK, S., «Gay fathers' motivations for and feelings about surrogacy as a path to parenthood», Human Reproduction, vol. 32, núm.4, 2017, p.863. 
«No estaba en pareja, soy gay y decidí explorar las diversas opciones que podía haber [para ser padre]. Principalmente hay tres grandes opciones: monoparentalidad, adopción o subrogación. A mí me cerraba la última opción así que me contacté con un médico que me dio una donante de óvulos y con eso produje una serie de embriones. Después busqué y encontré una señora que llevó el embarazo. Así estamos armando la familia. [...] La adopción es un camino sinuoso y bastante tortuoso en Argentina actualmente. La gente que conozco que se puso en proceso de adopción terminaron diciéndole: "esto puede nunca ocurrir". Algo tan aleatorio no me interesaba porque es una situación de tener que esperar sin depender de uno. [...] En algún punto, estando la posibilidad de tener un hijo genéticamente mío, me resulta más tentador la subrogación que la adopción» [E1, varón, monoparental, GS Argentina].

«Pasamos por varias etapas. En un comienzo teníamos intenciones de adoptar. Hicimos todos los trámites en el Registro Único de Aspirantes a Guarda con fines Adoptivos. Quedamos en la lista de espera y nos dimos cuenta que eso iba a ser tarea muy difícil entonces optamos por la subrogación. [...] Decíamos sabemos que la prioridad la va a tener una pareja heterosexual, porque hay jueces muy conservadores. Entonces dijimos no vamos a esperar eternamente. Había una cuestión de edad por ahí dando vueltas y no queremos ser los abuelos de un hijo» [E2, varón, pareja homosexual, GS extranjero].

«Nosotros estábamos decididos que queríamos ser padres. Y queríamos agotar todas las instancias. Entonces lo primero que se nos pasó por la cabeza es de alquilar un vientre porque yo no tengo útero. [...] Y hace cinco años que empezamos con tratamientos: se puede operar, no se puede operar, no hay manera, y los óvulos eran de buena calidad. Entonces ahí lo primero que empezamos a buscar fue la persona [gestante]. [...] Decíamos en la gestación tenía nuestro ADN. Entonces lo veíamos como una opción más cercana» [E4, pareja heterosexual, GS Argentina].

\section{La filiación bio-genética y la filiación con donación de gametos: ¿Es un hijo propio? ¿Me reconocerá como madre? ¿Me querrá igualmente?}

En la introducción del artículo expusimos sintéticamente la concepción euro-americana del parentesco que establece los vínculos en base a compartir sustancias bio-genéticas y semejanzas físicas entre padres e hijos. Estos elementos emergieron en el análisis de las opiniones de los usuarios de las TRHA manifestándose con fuerza y, a la vez, presentando matices cuando las opiniones se remitían a los planos individuales, sociales, afectivos y psicológicos.

Del análisis de las opiniones de los entrevistados surge que las preguntas en torno a lo decisivo de los componentes bio-genéticos para establecer vínculos de parentesco comienzan desde el momento en que los usuarios reciben la noticia sobre la necesidad de recurrir 
a la donación de gametos para intentar convertirse en madres o padres. En ese momento, los entrevistados describieron el comienzo de un proceso que los enfrenta a definir cuáles son los deseos que quieren cumplir, reflexionar críticamente sobre la preponderancia de los componentes bio-genético como rasgo cultural en la sociedad en la que viven, y emergen miedos y dudas. En particular, la necesidad de la ovodonación genera en algunas mujeres dudas respecto a considerar a un hijo propio cuando no hay vinculación genética, y solo considerarlo como propio con el ocultamiento del uso de esta técnica. También la ovodonación genera miedos sobre la futura consideración de ser la madre o ser digna del afecto de un hijo/a cuando no se aportó el material genético para su concepción ${ }^{34}$. Incluso alguna entrevistada manifestó la imperiosa necesidad de tener un vínculo genético aunque sea unilateral para considerar a un hijo como propio.

«Fue el cimbronazo más fuerte cuando descubrimos que no iba a ser con mis óvulos y no iba a llevar mi carga genética. Ahí empiezan a surgir un montón de cuestiones que uno no piensa ni reflexiona: por qué un hijo con tu genética, por qué querés tener un hijo con tu óvulo sí o sí y no con el óvulo de otra. Por eso está bueno la terapia y empezar a ir viendo: “¿Qué es lo que querés? ¿Tener un hijo? Sí, va a ser tu hijo de la manera que sea. Fue un proceso hasta que decidí la ovodonación. [...] Y siempre está el miedo porque hasta que las cosas no suceden no sabés qué va a pasar, no sabés que vas a sentir» [E 10, pareja heterosexual, ovodonación].

«Son miedos que uno tiene. Una vez que me hice el tratamiento nunca más pensé en [la ovodonación] porque me olvidé. El hecho de que me hayan donado un óvulo es para ayudarme a mí a ser mamá pero la nena es mía. A veces me da cosita pensar si mañana me pregunta de dónde salió el óvulo donado o que piense que tiene otra mamá...Por eso, no se lo pensamos decir ni se lo dijimos a nadie. [...] Es como un hijo adoptado que quiere salir a buscar a la familia biológica y me quiere menos. Es arcaico pero es mi personalidad» [E8, pareja heterosexual, ovodonación]. «El único miedo que particularmente me aparece, que en algún momento sentí, fue el miedo de que no me quisiera como su mamá y que a mi pareja sí porque fue su mamá gestante. Que en algún momento me rechace o me marque que no sea su madre» [E4, pareja de mujeres, espermadonación].

«Yo quería tener un hijo pero quería que tuviera por lo menos el $50 \%$ de mi material genético. No sé si tan fácilmente hubiera aceptado las dos donaciones. No sé si hubiera pesado más el deseo de ser madre y hubiera podido pasar esa traba. Me cuesta pensar que iba a ser con donante de ambos lados» [E6, mujer sin pareja, espermadonación].

\footnotetext{
34 Iguales resultados respecto de los sentimientos frente a la ovodonación se registraron en usuarias de TRHA, heterosexuales, que se encontraban realizando tratamientos, y todavía no habían tenido un hijo en 2011. Para profundizar, vid. STRAW, C., Público y privado en la reproducción asistida: oposición permanente. Estudio cualitativo en mujeres de sectores populares y medios residentes en el Área Metropolitana de Buenos Aires, ob. cit. pp.111-119.
} 
También hubo entrevistadas que plantearon con claridad la falta de importancia de compartir componentes bio-genéticos para establecer lazos filiales argumentando que estos se construyen con independencia incluso de los aspectos legales. Asimismo algunas entrevistadas enfatizaron la oposición rotunda a la creencia biologicista que imperan en la sociedad actual, y cómo - en el contexto socioafectivo de una pareja de mujeres-prevaleció la voluntad y el deseo de tener un hijo para decidir realizar tratamientos reproductivos que no privilegiaran dichas creencias.

«No era importante [compartir sustancias bio-genéticas]. No fue importante en su momento y hoy lo sigo sosteniendo. No me parece que valide nada [...] Se pone delante como para justificar un vínculo. A mí me parece que los vínculos se construyen más allá de lo genético, más allá de lo biológico, más allá de lo filiatorio, más allá de los papeles, más allá de las leyes» [E2, pareja de mujeres, espermadonación].

«La verdad que la sexualidad no está vinculado a algo biológico entonces tampoco el proyecto de familia está vinculado a algo biológico o genético. Queríamos tener un hijo y era una manera [recurrir a un tratamiento con esperma donado]. Somos todas personas adultas que acuerdan, la ciencia lo permite, todo está dentro del marco de una realidad, todo el mundo se maneja siempre con la verdad... Esas son las cosas que nos importaban. [...] No hicimos tampoco eso que algunas parejas de mujeres hacen, que a mí me parece una cagada, lo de la ovodonación [dona el óvulo la otra mujer no gestante de la pareja]. Esa ovodonación me parece una cagada porque es volver a determinados patrones biologisistas. Es volver atrás, aclaro para una pareja de dos chicas que una le done los óvulos a la otra, y [la obliga] a hacer una técnica mucho más compleja» [E2, pareja de mujeres, espermadonación].

En las opiniones de las entrevistadas citadas puede advertirse las diferentes concepciones de la maternidad que tenían como punto de partida: unas centradas en concepción ligada al hecho de compartir sustancias bio-genéticas, y otras a una concepción fundada en la voluntad y el deseo de tener un hijo. Asimismo se puede notar cómo -a lo largo de sus trayectorias y con la realización de los sucesivos tratamientos-van sustituyendo en las primeras la relevancia de los componentes bio-genéticos y otorgando importancia a los elementos volitivos para concebirse como madres ${ }^{35}$.

\footnotetext{
35 Respecto de estos cambios en la concepción y representación del parentesco en España, vid. RUBIO JOCILES, M.I., y RIVAS, A.M., «Cambios en la concepción y representación del parentesco a raíz del uso de las técnicas de reproducción asistida con donante», Ankulegi. Revista de Antropología Social, núm. 20, 2016, p. 68 .
} 


\section{La figura de donante y de la gestante y sus interpretaciones en relación con la filiación}

Algunos entrevistados que realizan tratamientos reproductivos con donación de gametos confunden la figura de donante de gametos con la de progenitor (madre o padre). Lo mismo se menciona respecto de las conversaciones que mantienen con personas de su entorno más cercano. Dos tipos de presunciones surgen del análisis de sus opiniones: por un lado, que un donante podría convertirse en un posible sujeto que reclame la maternidad o paternidad de un/a hijo/a; y, por otro lado, que los hijos nacidos utilizando gametos donados quieran en un futuro buscar «al padre»o «la madre» que donó el material genético. Iguales presunciones fueron registradas en un estudio realizado en España con fuentes primarias recogidas de parejas homoparentales (lesbianas o gays), heteroparentales y mujeres sin pareja y fuentes secundarias relevadas en sitios webs y foros ${ }^{36}$.

«Yo siento que puedo encontrarme con alguien que venga a reclamar una paternidad. Me parece que no, pero si pasa no me resultaría extraño» [E7, mujer sin pareja, espermadonación].

«Queremos tener otro hijo, y nos parece valioso que nuestro hijo pueda tener un hermano que comparta la genética, que tengan algo en común. El día de mañana si ellos dos juntos quieren salir a buscar a su padre será otra cosa» [E1, pareja heterosexual, espermadonación].

Sin embargo, otros usuarios entrevistados no confunden la figura del donante con un padre o una madre ni sostienen que el donante tenga un vínculo filial con el niño/a nacido. Incluso alguna entrevistada objetó la expresión «madre biológica»para referirse a una donante de óvulos. Iguales opiniones fueron registradas en un estudio en España en el caso de parejas gays en donde consideraban inadecuado utilizar el término madre para referirse a la donante de óvulos, en particular en un modelo de familia en el que claramente no había madre sino dos padres ${ }^{37}$. De todas formas, los entrevistados creen necesario educar y reforzar las ideas sobre qué es un donante y la inexistencia de vínculo filial cuando media una donación de gametos, así como sobre la diferencia entre un padre o una madre y material genético. En relación con la necesidad de reforzar estas distinciones, en un estudio reciente, mujeres sin pareja que recurrieron a tratamientos con donación de esperma en clínicas de Londres resaltaron que habían puesto un gran cuidado en no describir al donante como una figura paterna ${ }^{38}$.

\footnotetext{
36 RUBIO JOCILES, M.I., RIVAS, A.M., «Cambios en la concepción y representación del parentesco a raíz del uso de las técnicas de reproducción asistida con donante» ob. cit. p. 73.

37 RUBIO JOCILES, M.I., RIVAS, A.M., «Cambios en la concepción y representación del parentesco a raíz del uso de las técnicas de reproducción asistida con donante» ob. cit. p. 70.

38 ZADEH, S., FREEMAN, T., GOLOMBOK, S., «Absence or presence? Complexities in the donor narratives of single mothers using sperm donation». Human Reproduction, vol.31, núm.1, 2016, p.119.
} 
Igualmente los relatos de los entrevistados, que no confundieron la figura de donante de gametos con un progenitor ni establecieron un vínculo filial con los niños nacidos, muestran que la figura de donante tiene aristas controvertidas porque la vincularon al tipo de donación de gametos anónima y con donante conocido. Del análisis de sus opiniones vuelve a surgir que ante la eventualidad de la donación de gametos por un donante conocido se especula sobre la posibilidad de un reclamo de paternidad ${ }^{39}$.

«A los 18 años quedarán en libertad, estarán en todo su derecho de ir a tocar el timbre al médico y preguntar: ¿quién fue el donante?, pero para eso ya van a entender que el concepto de donante no es un padre» [E9, mujer sin pareja, espermadonación].

"Casi todos tenemos el fantasma del adolescente enojado porque no lo dejé ir a bailar que me diga: "no sos mi mamá" aunque lo sepan y lo puedan entender que no es su mamá [la donante]. Igual hay que explicárselo. Aparte una vez en un estudio que me habían mandado decía: madre biológica y otro tipo de madre que ahora no recuerdo el nombre. Y yo me recalenté, no es la madre biológica. Entonces fui [al diccionario de] la Real Academia Española a buscar el término "madre" y decía: "la que da a luz". Entonces ¿qué madre biológica? No hay otra madre» [E 6, pareja heterosexual, ovodonación].

«Para mí un donante es anónimo. Me parece que la palabra donante a lo que se refiere es a eso a quien dona. Justamente es donante porque renuncia a la voluntad de paternar si no sería un padre. Y un padre no es un material genético [...]. No me parece que tampoco para un donante sea bueno el hecho de perder el anonimato» [E2, pareja de mujeres, espermadonación].

\section{A. Las particularidades del donante conocido o intrafamiliar}

Los entrevistados al referirse a la figura del donante conocido o intrafamiliar mencionaron aspectos similares y diferentes a los descriptos en el apartado anterior. Entre los aspectos similares se destaca que recurrir a un donante conocido o intrafamiliar favorece situaciones problemáticas donde se confunden los roles familiares e incluso la interpretación distorsionada entre donante y progenitor en niños/as que hayan nacido, en particular, en familias monoparentales.

Entre los aspectos diferentes, algunas mujeres sin pareja que precisamente se oponían a recurrir a la donación de esperma de una persona conocida mencionan que la situación

\footnotetext{
39 Para profundizar sobre las preferencias de los usuarios TRHA respecto de los tipos de donaciones y los sentimientos que les despiertan los donantes, vid. STRAW, C., DE LA TORRE, N., BLADILO, A., y SALITURI AMEZCUA, M., «Anexo II. Resultados de la investigación. Trayectorias sociojurídicas de la reproducción asistida cuando involucra a un tercero (donante o gestante). De identidades y filiaciones en plural» ob. cit. pp. 601-645.
} 
podría interpretarse como un acuerdo de coparentalidad o una posible triple filiación no prevista legalmente en la Argentina.

«No, nunca [donante conocido ni intrafamiliar]. Porque yo quería ser mamá sola y no quería tener que compartir a mi hijo con nadie que no fuera una pareja estable. No importa que sea amigo o persona conocida porque después ese vínculo no lo podés romper y se vuelve medio confuso para mi hija. Eso es mucho más complejo que recurrir a la donación anónima, incluso más fácil para explicarle a [un hijo] cuando arranque con las preguntas» [E8, mujer sin pareja, espermadonación]. «Me pareció una locura tremenda [recurrir a un donante conocido] y siempre como que tomamos esta idea de los institutos [de medicina reproductiva]. Nunca lo planteamos como una posibilidad. Además teníamos una especie de fantasía, que no fue más que eso, porque me pareció muy rara alguna amistad pero un familiar me parece más extraño todavía. Siempre planteamos la idea de la confusión y la otra persona que después ve el parecido y dice "en realidad es un poco hijo mío". Esto se puede plantear y entonces no» [E 12, pareja heterosexual, ovodonación]. «Tampoco tenía a nadie que pudiera ser [donante conocido] pero alguna vez alguien que me consulto y yo le dije que no estaba bueno un donante conocido. Digamos que para hacer una coparentalidad tiene haber como acuerdos muy muy claros. Y me parecía que podía ser más peligroso después las decisiones sobre tu hijo, educación... Si hay problemas con las parejas que se casaron y decidieron tener un hijo juntos... a la larga [tener un donante conocido] podía traer problemas» [E3, mujer sin pareja, espermadonación].

«No queríamos un reclamo de paternidad de otra persona [que fuera donante conocido]. Y por lo que habíamos leído de la ley no contemplaba una triple filiación. [...] Ahí sí fue un tema más egoísta de nosotras. Nuestra familia la pensamos nosotras dos nada más. Es nuestro proyecto de familia. Nosotras y nuestra hija o nuestros hijos» [E4, pareja de mujeres, espermadonación].

Opiniones similares respecto de favorecer situaciones problemáticas como la confusión de los roles familiares surgieron entre los usuarios que realizaron una GS, y analizaban la posibilidad de recurrir a un donante conocido o una gestante conocida. Estos usuarios destacaron con énfasis la necesidad de no confundir a un donante de gametos con una madre o un padre, ni atribuirle vínculos filiales con los nacidos.

«La donante va a estar metida siempre en nuestras conversaciones con [nuestro/a hijo/a] como donante, porque muchos te dicen "bueno porque la madre", no, no, es la donante no va a tener el rótulo de mamá, va a ser la donante, va a ser alguien que en su vida, ojalá, no sé qué va a pasar en el futuro, pero va a tener un cierto grado de importancia desde ese lugar de ser la mujer que posibilitó que alguien naciera, como la subrogante también» [E2, varón, pareja homosexual, GS extranjero]. 
«Mucho no me convence [gestante intrafamiliar]. Es más práctico que sea alguien ajeno a la familia porque la cuestión intrafamiliar puede traer confusiones de roles. [...] Yo no lo contemplaría personalmente. Me parecería raro, y cuando lo leí en el anteproyecto me parecía raro. Es menos enquilombado con alguien ajeno» [E1, varón, monoparental, GS Argentina].

\section{Las particularidades de la GS: la importancia de la regulación legal del tratamiento y de la filiación}

El vacío legislativo respecto de la GS en la Argentina genera incertidumbre y dificultades en aspectos vinculados a la filiación que influyen en numerosas decisiones que tuvieron que tomar los entrevistados: realizar o no la GS en el país o en el extranjero, procesar situaciones irregulares consistentes en que la persona gestante figure como madre en la partida de nacimiento del niño/a nacido/a, o rechazar acuerdos ilegales con las partidas de nacimiento para que figure como madre quien no parió al niño/a, no firmó un consentimiento informado ni expresó la voluntad procreacional, y que desaparezca de escena la gestante y la GS realizada.

Por otra parte, los usuarios que realizaron una GS resaltaron la importancia de lo legal y la vinculación con la filiación porque recién pensaron más seriamente en la paternidad con sus parejas gays a partir de la sanción de la ley de matrimonio igualitario, y el resguardo legal que garantizaba. Asimismo mencionaron que la decisión de realizar la GS en el extranjero se basó precisamente en las protecciones legales del tratamiento, y del reconocimiento a las parejas homoparentales como padres del niño/a que naciera.

«Está fuera de la ley porque hasta ahora [la gestante] aparece como madre en el certificado de nacimiento. Es un proceso que al no estar encuadrado legalmente es tirarte a la pileta y estás en manos de cierto destino. No es angustioso pero es sentir que no estás amparado. Todo depende de la buena voluntad de las partes. Es una sensación molesta porque uno genera confianza con la gestante pero también uno sabe que cualquier cosa que pase y ella decide tener [la/el niña/o] ya empieza una batalla legal con un resultado incierto» [E1, varón, monoparental, GS Argentina]. «Acá no estaba regulado [la GS] con lo cual sigue siendo una duda la paternidad. Por más que sea por subrogación sigue siendo una copaternidad [ser reconocidos los integrantes de la pareja como padres]. No hay mucha vuelta que darle. Esa era nuestra opción. Después esto se empezó a hablar seriamente cuando salió la ley de matrimonio igualitario porque no sé si tampoco lo hubiéramos hecho antes. [...] Era como raro porque al no existir una ley de matrimonio el hijo iba a ser de uno. $Y$ las cosas se fueron dando. Después fuimos a ver una abogada porque otro tema era si íbamos a poder anotar al niño/a acá [en Argentina]. Y nos dijo: "mira acá no lo van a poder anotar. Para una mujer es distinto porque como lo parió ella, y si está casada con una mujer, lo anota como cónyuge pero ustedes dos [varones] tal 
cual así no". [...] Para mí la única opción era hacerlo en Estados Unidos porque hay una ley que te protege, que protege al niño, donde en su partida de nacimiento dice que es hijo de Juan y Pedro y no de Juan y fulanita, y donde fulanita no se puede arrepentir» [E3, varón, pareja homosexual, GS extranjero].

«Yo tenía que conseguir una persona y tenía que hacer [la GS] de una forma totalmente irregular. [...] No está legislado en Argentina el tema de la subrogancia. Y el problema es: ¿qué pasa si la mujer, la que tiene el bebé en el vientre se lo quiere quedar? La realidad es que si se lo quiere quedar es de ella. [...] Te ofrecen hacerlo pero te ofrecen hacer algo que es cometer un delito. Porque al nacer en los sanatorios el médico te ofrece sin decírtelo una partida de nacimiento donde aparece como madre no la que está pariendo que si bien el niño nace de forma biológica, ponen el nombre de su madre no biológica. Y en realidad es una falsedad ideológica, es un documento de orden público. Eso es lo que nosotros no aceptamos por la cuestión legal» [E5, pareja heterosexual, GS extranjero].

Como puede apreciarse de las opiniones de los entrevistados citadas, las situaciones que tienen que afrontar las personas que realizan una GS en Argentina y en el extranjero son diferentes en cuanto a la determinación del vínculo filial y la judicialización de los procesos para establecerla. Quienes realicen una GS en la Argentina tienen que enfrentar un proceso judicial para declarar la inconstitucionalidad del artículo 562 de CCyC dado que es el que establece que «los nacidos por las técnicas de reproducción humana asistida son hijos de quien dio a luz», mientras que para quienes realicen una GS en el extranjero, el emplazamiento del reconocimiento filial se encuentra contemplado en el artículo 2634 del CCyC citado precedente, y evita la judicialización de sus casos, aunque pueden surgir complicaciones al momento de realizar los trámites filiatorios en los Registros Civiles ${ }^{40}$.

\section{CONCLUSIONES}

Las tecnologías reproductivas multiplican las posibilidades para conformar diferentes modelos de familias en el marco de procesos de cambios socioculturales en los que los componentes bio-genéticos para establecer los vínculos de parentesco todavía continúan predominando, independientemente de la orientación sexual de las personas o la conformación del modelo familiar (nucleares, monoparental, homoparental o comaternal).

En especial quienes conforman familias diversas reconocieron sentir miedos y dudas sobre el grado de aceptación o de rechazo social de familias sin padre o madre, o con dos padres o dos madres aun contando con una ley de matrimonio igualitario que prevé la paternidad y maternidad compartida en parejas integradas por gays o lesbianas desde 2010 .

\footnotetext{
40 Una descripción de las estrategias legales desarrolladas por quienes realizaron una GS en la Argentina así como los inconvenientes suscitados en la tramitación en los Registros Civiles de quienes la realizaron en el extranjero puede consultarse en NOTRICA, F. y CURTI, P. «Capítulo VI: Gestación por sustitución», ob. cit. pp. 90-139.
} 
Del análisis de las opiniones de los usuarios resulta evidente que en la filiación derivada por el uso de las tecnologías reproductivas predomina el elemento volitivo por sobre los elementos bio-genéticos. De todas formas, la voluntad y el deseo de tener un/a hijo/a no suprime la necesidad de un proceso de reflexión donde se procesa la discontinuidad bio-genética para considerar a un hijo como propio, considerarse madre y eventualmente superar los miedos respecto a que un/a hijo/a reconozca y quiera a una madre con la cual no tiene vinculación genética o bio-genética.

Los cambios culturales y legislativos tendientes a la apertura y/o aceptación hacia la diversidad sexual y el tratamiento igualitario entre las personas homosexuales y heterosexuales fueron reconocidos como factores que favorecieron la toma de decisiones pero para ello fue necesario que la voluntad y el deseo de ser madres o padres se imponga a las ideas predominantes en la sociedad. El fantasma de los usuarios relativo a un donante o una gestante reclamando la paternidad o maternidad de un/a hijo/a, o un/a hijo/a buscando a un padre o una madre en un donante o una gestante pone de manifiesto cómo continúan subyaciendo los componentes biologicistas para la atribución del parentesco en la sociedad actual.

También estudios realizados en España, Reino Unido y los Estados Unidos muestran que estos rasgos culturales continúan presentes cuando personas o parejas prefieren realizar un TRHA para intentar tener un hijo antes que adoptar uno, mujeres dudan respecto de los vínculos con sus hijos cuando necesitan realizar tratamientos de ovodonación, parejas gays o heterosexuales deciden realizar una gestación por sustitución para mantener la vinculación genética con su descendencia.

El nuevo Código Civil y Comercial argentino ha sido un profundo avance respecto de la filiación en contextos tecnológicos al reconocer su especificidad en un tipo filial autónomo. Igualmente con solo tres años de vigencia los miedos, las dudas y las confusiones expresadas por los entrevistados en nuestra investigación, muestran que debe ponerse el esfuerzo en difundir muchos de sus contenidos para multiplicar y legitimar socialmente los cambios culturales que el Código contiene en lo relativo al derecho de las familias.

También la reforma del Código ha significado una oportunidad perdida al no legislar sobre la GS cuando se disponía de una propuesta concreta que contemplaba la intervención judicial y el respeto a los derechos de la gestante y los comitentes. Tampoco se ha avanzado desde la sanción del Código en 2015 con la sanción de una ley especial que regule integralmente las TRHA. Esto además de generar numerosas lagunas normativas en aspectos centrales de la aplicación de las tecnologías reproductivas, también pone en riesgo el cumplimiento de contenidos del Código como es el derecho a conocer los orígenes a los nacidos por tecnologías reproductivas porque no se han creado los registros de donantes de gametos y gestantes bajo la responsabilidad del Estado nacional.

En estas páginas he querido resaltar el ejercicio de la autonomía de la voluntad de usuarios de las tecnologías reproductivas y la importancia de los cambios culturales y legislativos en torno de la filiación. En la Argentina numerosas cuestiones restan legislar y 
varios tabúes quedan por develar si lo que se quiere es alcanzar una sociedad democrática, pluralista, previsible e igualitaria acorde a los avances y desarrollos de la ciencia.

\section{BIBLIOGRAFÍA}

BESTARD, J., «Los hechos de la reproducción asistida: entre el esencialismo biológico y el constructivismo social». Revista de Antropología Social, Universidad Complutense de Madrid, núm.18, 2009, pp. 83-95.

BLAKE, L., CARONE, N., RAFFANELLO, E., SLUTSKY, J., EHRHARDT, A.A., and GOLOMBOK, S., «Gay fathers' motivations for and feelings about surrogacy as a path to parenthood», Human Reproduction, vol. 32, núm. 4, 2017, pp. 860-867.

MARRE, D. y BESTARD, J., La adopción y el acogimiento. Presente y perspectivas, Barcelona, (Universitat de Barcelona), 2004.

HERRERA, M., DE LA TORRE, N., SALITURI AMEZCUA, M., RODRÍGUEZ ITURBURU, M., y VITTOLA, L., «Capítulo V: Filiación derivada de técnicas de reproducción humana asistida: voluntad procreacional y consentimiento informado» en HERRERA, M. (dir.), Técnicas de Reproducción Humana Asistida, Buenos Aires (Rubinzal - Culzoni Editores), 2018, pp. 435-647.

HERRERA, M., «¿Existe un derecho al hijo? El lugar y los límites de las técnicas de reproducción humana asistida», RJUAM, núm. 35, 2017, pp. 73-113.

HERRERA, M., LAMM, E., «Cobertura médica de las técnicas de reproducción asistida. Reglamentación que amplía el derecho humano a formar una familia», Revista La Ley, núm. 140, 2013, pp. 1-6.

HERRERA, M. y LAMM, E., «Una trilogía sobre las bases constitucionales del derecho filial en el Anteproyecto de reforma del Código Civil: Técnicas de reproducción humana asistida (Bleu)», Diario Microjuris, (MJAR), Buenos Aires, 2012, pp. 1-29.

HERTZ, R., RIVAS, A.M., RUBIO JOCILES, M.I., «Single Mothers by Choice in Spain and the United States», en CONSTANCE, L. SHENAN (ed.) The Wiley Blackwell Encyclopedia of Family Studies, $1^{\text {a }}$ ed., New York (John Wiley \& Sons, Inc.), 2016, pp.1-5. Disponible en <https://doi.org/10.1002/9781119085621. wbefs005>

JENNINGS, S., MELLISH, L., TASKER, F., LAMB, M., GOLOMBOK, S., «Why adoption? Gay, lesbian, and heterosexual adoptive parents'reproductive experiences and reasons for adoption». Adopt Q, vol. 17, 2014, pp. 205-226. 
KEMELMAJER DE CARLUCCI, A., «La autonomía de la voluntad en el derecho de familia argentino» en GRAHAM, M. y HERRERA, M. (dirs.), Derecho de las Familias, Infancia y Adolescencia. Una mirada crítica y contemporánea, 1. ${ }^{\mathrm{a}}$ ed., Ciudad Autónoma de Buenos Aires (Infojus), 2014, pp. 3-43. Disponible en $<$ http://www.saij.gob.ar/aida-kemelmajer-carlucci-autonomia-voluntad-derechofamilia-argentino-dacf140453-2014-07/123456789-0abc-defg3540-41 fcanirtcod> [Consultado el 5/9/18].

KEMELMAJER DE CARLUCCI, A., HERRERA, M., y LAMM, E., «Filiación y homoparentalidad. Luces y sombras de un debate incómodo y actual». Revista La Ley, núm. 1, 2010, pp. 1-31.

KEMELMAJER DE CARLUCCI, A., HERRERA, M., y LAMM, E., «Ampliando el campo del derecho filial en el derecho argentino. Texto y contexto de las técnicas de reproducción humana asistida». Revista de Derecho Privado, vol. 1, núm. 1, 2012, pp. 3-45. Disponible en <http:/www.uba.ar/archivos_ddhh/image/2012RevistaInfojusFinal.pdf $>$ [Consultado el 20/1/19].

LAMM, E., «La importancia de la voluntad procreacional en la nueva categoría de filiación derivada de las técnicas de reproducción asistida», Revista de Bioética y Derecho, núm. 24, 2012, pp. 76-91.

MINYERSKY, N., «El impacto del proyecto del Código Civil y Comercial de la Nación en instituciones del derecho de familia», Revista Pensar en Derecho, vol. 1, núm. 0, 2012, pp. 69-115. Disponible en <http:/www.derecho.uba.ar/ publicaciones/pensar-en-derecho/revistas/0/el-impacto-del-proyecto-del-codigocivil-y-comercial-de-la-nacion-en-instituciones-del-derecho-de-familia.pdf> [Consultado el 5/9/18].

RUBIO JOCILES, M.I., y RIVAS, A.M., «Cambios en la concepción y representación del parentesco a raíz del uso de las técnicas de reproducción asistida con donante», Ankulegi. Revista de Antropología Social, núm. 20, 2016, pp. 63-78.

SCHNEIDER, D., A Critique of the Study of Kinship, Ann Arbor, (University of Michigan Press), 1984.

STRATHERN, M., Reproducing the future: Anthropology, kinship and the new reproductive technologies, New York (Routledge), 1992.

STRATHERN, M., «A Antropologia e o advento da Fertilização In Vitro no Reino Unido: uma história curta». Caderno Pagu, núm. 33, 2009, pp. 9-55.

STRAW, C., Público y privado en la reproducción asistida: oposición permanente. Estudio cualitativo en mujeres de sectores populares y medios residentes en el Área Metropolitana de Buenos Aires. Berlín (Publicia), 2014. 
STRAW, C., VARGAS, E., VIERA CHERRO, M., TAMANINI, M. (coords.), Reprodução assistida e relações de gênero na América Latina, Editora CRV, Curitiba, 2016.

STRAW, C., DE LA TORRE, N., BLADILO, A., y SALITURI AMEZCUA, M., «Anexo II. Resultados de la investigación. Trayectorias sociojurídicas de la reproducción asistida cuando involucra a un tercero (donante o gestante). De identidades y filiaciones en plural» en HERRERA, M., Técnicas de Reproducción Humana Asistida, Buenos Aires (Rubinzal - Culzoni Editores), 2018, pp. 587- 645.

ZADEH, S., FREEMAN, T., GOLOMBOK, S., «Absence or presence? Complexities in the donor narratives of single mothers using sperm donation». Human Reproduction, vol. 31, núm.1, 2016, p.119. 